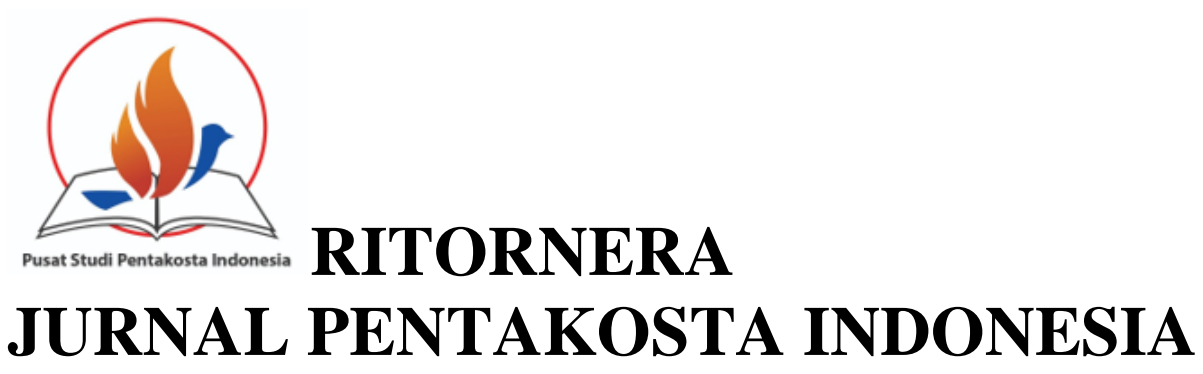

Vol. 1, No. 3, Desember 2021

Available at: pspindonesia.org

\title{
Tinjauan Eksistensi Roh Kudus dalam Dunia Virtual
}

\author{
Sarah Priska Toding 1 \\ todingsarahtoding@gmail.com \\ Carolina Etnasari Anjaya² \\ carolina.anjaya@gmail.com
}

\begin{abstract}
This research is structured in order to provide an understanding to believers that the current virtual world has actually moved away from the quality of life that God wants. Even though God has given the Holy Spirit as a true guide for life. The research method uses a qualitative type, through reading and analyzing various relevant literature and basing the theory of understanding on the biblical text. The results show that life in the virtual era does not involve the Holy Spirit in it. This does not mean that the Holy Spirit does not exist and is unable to intervene in circumstances, but this is related to the free will that God gives to believers. The existence of the Holy Spirit needs to be presented to the life of the virtual world as the only guide. In this regard, there are several concrete steps that believers can take in order to be witnesses and glorify God in today's virtual life.
\end{abstract}

Keywords: Holy Spirit; virtual world; Christian education; existence of spirit; bible view

\begin{abstract}
Abstrak
Penelitian ini disusun agar dapat memberikan pemahaman kepada umat percaya bahwa kehidupan dunia virtual saat ini sejatinya telah bergerak menjauh dari kualitas kehidupan yang dikehendaki Tuhan. Padahal Tuhan telah memberikan Roh Kudus sebagai penuntun hidup yang benar. Metode riset dengan mempergunakan jenis kualitatif, melalui pembacaan dan analisa terhadap berbagai literatur yang relevan dan melandaskan teori pemahaman pada teks Alkitab. Hasil penelitian menunjukkan bahwa kehidupan dalam era virtual tidak melibatkan Roh Kudus di dalamnya. Hal ini bukan berarti Roh Kudus tidak ada dan tidak mampu mengintervensi keadaan, namun ini bertalian dengan kehendak bebas yang Tuhan berikan kepada orang percaya. Eksistensi Roh Kudus perlu dihadirkan pada kehidupan dunia virtual sebagai satu-satunya penuntun. Bertalian dengan hal tersebut terdapat beberapa langkah konkrit yang dapat dilakukan oleh umat percaya agar dapat menjadi saksi dan memuliakan Tuhan dalam berkehidupan virtual masa kini.
\end{abstract}

Kata kunci : Roh Kudus; Dunia virtual; Pendidikan Kristen; Eksistensi Roh; Pandangan alkitab

${ }^{1}$ Sekolah Tinggi Teologi Transformasi Indonesia

${ }^{2}$ Sekolah Tinggi Teologi Ekumene Jakarta

Copyright(C) 2021; Ritornera - Jurnal Teologi Pentakosta Indonesia ISSN 2797-7676 (online), 2797$717 \times$ (print) $\mid 1$ 


\section{PENDAHULUAN}

Masuk pada era internet of things ( IoT) saat ini kehidupan manusia telah ditopang oleh kekuatan teknologi informasi komunikasi sehingga kenyamanan dan kemudahan menjadi sesuatu yang pasti di zaman ini. Inilah hakikat dari penciptaan teknologi menurut Marpaung. ${ }^{1}$ Teknologi telah membawa manusia hidup dalam satu ruang besar dunia sebagai kesatuan relasi antara dunia maya dan nyata. Terlebih karena pandemi Covid-19 telah menjadi katalisator peralihan formasi kehidupan nyata kepada virtualitas. Apapun kebutuhan manusia, dunia maya menggenapinya secara lengkap. ${ }^{2}$ Situasi ini membuat manusia begitu menikmati dunia virtual sebagai rumah baru yang dapat memberikan jawaban atas segala pertanyaan dan kepenuhan atas semua kebutuhan. Dalam dunia virtual, semua hajat manusia dapat dipenuhi dengan mudah dan instan. Situasi ini merangkai tata kehidupan dan format berpikir yang berbeda bagi mayoritas orang-termasuk orang percaya. Bahkan kini, bagi orang percaya kebutuhan tuntunan hidup, pertolongan, hiburan, kekuatan dan persahabatan setia dirasa telah tersedia dalam berbagai platform atau media virtual. Generasi virtual terbelit pada candu digital sehingga mengabaikan tanggungjawab di dunia riil dengan menanggalkan Tuhan. ${ }^{3}$ Tercipta asumsi dunia virtual dapat menggenapi seluruh kebutuhan secara instan sehingga kebutuhan akan Tuhan terpinggirkan. Sifat transenden tidak menggugah rasionalitas orang masa kini.

Ketidak-hadiran Tuhan dan rohNya yang dibangun oleh orang-orang percaya dalam dunia virtual dapat dibuktikan dengan berbagai penyimpangan tindak perilaku. Semisal terjadi fakta terdapat orang-orang yang mengalami depresi hanya karena komentar warganet dalam media sosialnya. Hal ini sesuai dengan temuan sebuah studi bahwa media sosial menjadi sebab gangguan mental pada orang Indonesia. ${ }^{4}$ Orang juga cenderung lebih memilih mengikuti nasehat dari ruang virtual daripada mencari hikmat Tuhan. Banyak orang lebih cocok dengan gaya hidup hedon, sesuai model yang dunia virtual tampilkan ketimbang mengikuti gaya hidup sederhana yang Tuhan Yesus ajarkan. Para penyampai firman Tuhan

\footnotetext{
1 Junierissa Marpaung, "Pengaruh Penggunaan Gadget Dalam Kehidupan," KOPASTA: Jurnal Program Studi Bimbingan Konseling 5, no. 2 (2018): 55, https://doi.org/10.33373/kop.v5i2.1521.

${ }^{2}$ Daruliansyah Yosa Putra, "Pengembangan Hubungan Interpersonal Remaja Di Sidoarjo Melalui Media Sosial," Ilmu Komunikasi Bl (3), 2018, 1.

${ }^{3}$ Ang Wie Hay, "Gaya Hidup Digital Kristiani Era Globalisasi," Jurnal Youth Ministry 3, no. 1 (2015): 51, https://doi.org/10.47901/jym.v3i1.429.

${ }^{4}$ Tim, "Medsos Sebabkan Gangguan Mental Pada Orang Indonesia,” CNN Indonesia, June 26, 2019, https://www.cnnindonesia.com/gaya-hidup/20190626100119-255-406497/medsos-sebabkan-gangguanmental-pada-orang-indonesia.
}

Copyright(C2021; Ritornera - Jurnal Teologi Pentakosta Indonesia, ISSN 2797-7676 (online), 2797$717 \times$ (print) $\mid 2$ 
pun terjebak pada gaya hidup hedon yang secara terang dipertontonkan di ruang publik digital. ${ }^{5}$ Orang percaya pun sudah mengadopsi sikap egois, konsumtif, materialistis, individualistis, serba instan dan rasionalistis. Ini semua menjadi karakteristik kehidupan era saat ini, keduniawian yang hedonis dan materialistis. ${ }^{6}$ Deskripsi ini mencerminkan orang percaya menyandarkan hidup kepada dunia virtual, bukan kepada Tuhan melalui tuntunan Roh KudusNya. Melansir dari laporan Tekno Kompas bahwa riset lapangan oleh sebuah media Inggris: We are Social merilis data orang Indonesia rata-rata berselanjar di dunia maya sekitar 3 jam sehari dengan total populasi pengguna 170 juta. $^{7}$ Catatan waktu ini meningkat ketika terjadi pandemi Covid-19. Data sebuah riset terhadap penggunaan internet tercatat seluruh populasi mengalami kecanduan media sosial tingkat rendah maupun tinggi masingmasing tingkatan sebesar 51.4 persen dan 18.6 persen. ${ }^{8}$ Data tersebut dipertegas oleh hasil riset penulis terhadap beberapa anak muda yang menyatakan bahwa waktu yang diluangkan untuk aktifitas rohani mencakup renungan, pembacaan Alkitab dan doa per hari hanya berkisar maksimal 1 jam. ${ }^{9}$ Dengan demikian dapat dinyatakan bahwa alokasi waktu untuk berdampingan dengan Roh Kudus sangatlah minim dalam keseharian hidup orang Kristen.

Riset mengenai keberadaan dan kebergantungan pada Roh Kudus telah banyak dilakukan, salah satunya membahas tentang peranan Roh Kudus dalam hidup orang Kristen yang disusun oleh Sumiwi. Pembahasan melahirkan simpulan bahwa Roh Kudus mendorong proses kelahiran baru, membawa pada pertobatan dan kekudusan, memberi kekuatan dan karunia. ${ }^{10}$ Peneliti lain adalah Arifianto masih pada seputar peran Roh Kudus bagi orang Kristen namun lebih menekankan pada landasan Yohanes 16:13. Disimpulkan oleh Arifianto Roh Kudus membawa kepada kelepasan dosa dan roh jahat, pemberi hikmat agar dapat hidup sepeti Tuhan, dan menuntun pada kebenaran Tuhan. ${ }^{11}$ Tubagus dan Sarono melakukan penelitian terkait Roh Kudus dengan tema Roh Kudus dan komunitas umat Allah,

5 Timotius Haryono and Daniel Fajar Panuntun, "Model Gaya Hidup Nazir Sebagai Refleksi Gaya Hidup Hedon Pengkotbah Pada Zaman Milenial," Evangelikal: Jurnal Teologi Injili Dan Pembinaan Warga Jemaat 3, no. 2 (2019): 175, https://doi.org/10.46445/ejti.v3i2.146.

6 Nuraini and Nelly Marhayati, "Analisis: Jurnal Studi Keislaman Peran Tasawuf Terhadap Masyarakat Modern,” Studi Keislaman 19, no. 2 (2019): 297.

${ }^{7}$ Conney Stephanie, "Riset Ungkap Lebih Dari Separuh Penduduk Indonesia,” Kompas.com, 2021, https://tekno.kompas.com/read/2021/02/24/08050027/riset-ungkap-lebih-dari-separuh-penduduk-indonesiamelek-media-sosial.

${ }^{8}$ Rizki Aprilia, Aat Sriati, and Sri Hendrawati, "Tingkat Kecanduan Media Sosial Pada Remaja," Journal of Nursing Care 3, no. 1 (2020): 41, https://jurnal.unpad.ac.id/jnc/article/view/26928.

${ }^{9}$ Riset, "Catatan Riset Remaja Pengguna Medsos" (Jakarta, 2021).

${ }^{10}$ Asih Rachmani Endang Sumiwi, "Peran Roh Kudus Dalam Kehidupan Orang Percaya Masa Kini," JURNAL TEOLOGI GRACIA DEO 1, no. 1 (December 14, 2018): 23-31, https://doi.org/10.46929/GRACIADEO.V1I1.19.

${ }^{11}$ Yonatan Alex Arifianto and Asih sumiwi Rachmani, "Peran Roh Kudus Dalam Menuntun Orang Percaya Kepada Seluruh Kebenaran Berdasarkan Yohanes 16 : 13,” Jurnal Diegesis 3, no. 1 (2020): 1-12. 
menyatakan manusia bertemu dengan Roh Kudus sebagai pribadi bagian dari tritunggal dalam dimensi spiritual. ${ }^{12}$ Tinjauan yang telah penulis tetapkan pada berbagai penelitian, sampai kepada penemuan gap riset yaitu belum tersusun pembahasan tentang pola kebergantungan orang percaya kepada Roh Kudus dalam kehidupan di era digital ini. Oleh karenanya penulis mengangkat penelitian ini dengan tujuan agar dapat memberikan sumbang pemikiran dan renungan bagi umat Tuhan tentang pemulihan kebergantungan hidup pada RohNya. Terutama di zaman ini dimana tawaran dunia virtual seolah lebih menjanjikan, instan dan riil daripada janji penyertaan Tuhan melalui Roh Kudus dalam kehidupan anak-anak-Nya.

\section{METODE}

Peneliti melakukan tinjauan berbagai literatur yang ada untuk dapat sampai kepada makna dan kesimpulan penelitian ini. Landasan yang dipakai sebagai arah pemikiran adalah teks Alkitab yang relevan. Observasi juga dilakukan sebagai pelengkap data empiris yang meneguhkan fakta bagaimana pada zaman ini terjadi pengabaian peran Roh Kudus dalam kehidupan. Oleh karena hal tersebut metode kualitatif deskritif ${ }^{13}$ dipakai untuk menyusun laporan penelitian ini. Sesuai dengan pendapat Zaluchu bahwa metode penelitian harus disampaikan secara sistematis dan memuat tahapan penelitian, ${ }^{14}$ maka pada bagian ini disajikan langkah-langkah riset yang dilakukan peneliti. Pada tahap awal peneliti menetapkan permasalahan. Dari hal tersebut dilanjutkan dengan studi pustaka, menentukan lokus dan penelitian pendahuluan. Pengumpulan data melalui observasi di lapangan juga dilakukan sebagai pelengkap data. Analisis data menjadi tahapan berikutnya, untuk kemudian ditarik sebuah kesimpulan.

\section{HASIL DAN PEMBAHASAN}

\section{Roh Kudus dalam Alkitab}

Kisah Para Rasul menceritakan tentang Roh Kudus yang Tuhan Yesus hibahkan kepada para rasul (Kisah 2:1-13). Tuhan Yesus secara mantap menyatakan bahwa

12 Steven Tubagus and Timotius Bakti Sarono, "Roh Kudus Dalam Trinitas Dan Komunitas Umat Tuhan (Holy Spirit in the Trinity and Community of God'S People)," QUAERENS: Journal of Theology and Christianity Studies 3, no. 1 (2021): 95, https://doi.org/10.46362/quaerens.v3i1.30.

${ }^{13}$ Sonny Eli Zaluchu, "Strategi Penelitian Kualitatif Dan Kuantitatif Di Dalam Penelitian Agama," Evangelikal: Jurnal Teologi Injili Dan Pembinaan Warga Jemaat 4, no. 1 (2020): 28, https://doi.org/10.46445/ejti.v4i1.167.

${ }^{14}$ Sonny Eli Zaluchu, "Metode Penelitian Di Dalam Manuskrip Jurnal Ilmiah Keagamaan,” Jurnal Teologi Berita Hidup 3, no. 2 (2021): 252, https://doi.org/10.38189/jtbh.v3i2.93. 
keberadaan Roh Kudus sebagai tanda deklarasi peralihan kehidupan para murid yang dikuasai oleh Roh Allah. Tuhan menyampaikan muridNya dibaptis dalam Roh Kudus (Kisah 1:5). Ini berarti suatu peringatan yang nyata kepada iblis bahwa Tuhan telah memilih anakanakNya untuk menjadi milik sepenuhnya - dilambangkan dengan baptisan (1 Korintus 6:19). Keadaan ini memastikan kendali dan kuasa Roh Kudus dalam seluruh lingkup hidup orang Kristen sehingga arah hidupnya hanya kepada apa yang Roh Kudus kehendaki. Hal ini memberi keterangan bahwa penguasaan Roh Kudus atas orang percaya membuat pemisahan antara kerajaan Tuhan dan dunia yang berada dalam kuasa iblis.

Penguasaan Roh Kudus atas kehidupan orang percaya Tuhan desain agar melaluinya akan mampu melihat Tuhan secara nyata karena Roh Kudus adalah pengganti kehadiranNya di dunia ini. Roh Kudus tinggal bersama pribadi Tuhan Yesus. Seperti halnya Stefanus ketika mengalami kepenuhan kuasa Roh Kudus, dia mampu melihat Tuhan dan kemuliaanNya secara riil. Bahkan lebih dari itu, Stefanus melihat kerajaan surga terbuka melalui mata jasmaninya dan terlihat Anak Manusia di sebelah Allah (Kisah 7:55-56). Penguasaan Roh Kudus tidak terlepas dari syarat pertobatan. Sebab ada dinyatakan bahwa hanya melalui pertobatan manusia akan dapat melihat kerajaan Tuhan. Dan keterkaitan ini memang benar dikarenakan Roh Kudus hanya akan diam di dalam kelahiran baru dan kekudusan (Kisah 2:38; 1 Korintus 6:11).

Roh Kudus adalah pendidik. Dia akan mengajarkan semua perkara yang Tuhan telah ajarkan. Selama pelayanan di dunia, Tuhan mendidik Petrus dan murid lainnya tentang kerajaan surga. Dan semua ajaran itu dialihtugaskan pada Roh Kudus ketika Dia kembali kepada BapaNya (Yohanes 14:26). Roh Kudus secara terus menerus akan memperbaharui orang percaya agar terdidik menjadi berkarakter Allah. Budiyana menyatakan bahwa ada keyakinan Roh Kudus secara detil ikut campur tangan bekerja sampai pada kegiatan belajar, dalam kotbah maupun pendalaman ajar Alkitab. Pendidikan yang telah Tuhan Yesus rintis di bumi terus berlanjut sampai era baru ini bersama Roh Kudus.

Anugerah kedua setelah penebusan Tuhan Yesus di salib adalah pemberian Roh Kudus dalam hidup orang Kristen. Bapa mengharapkan semua anakNya meminta kepada Dia sesuatu hal baik, yaitu kehadiran Roh Kudus (Lukas 11:13). Hal yang baik karena melewati pemberian tersebut, orang percaya akan mendapatkan anugerah kuasa dan mampu bersaksi bagi Tuhan di seluruh semesta (Kisah 1:8). Simon memberikan opini tentang Roh Kudus yang menyalurkan tekad dan keberanian pada seseorang untuk memberitakan kebenaran Tuhan. Keberanian Tuhan Yesus yang luarbiasa dimanifestasikan kepada orang percaya melalui transfer spirit Ilahi bersama Roh Kudus.Pengharapan, sukacita, damai 
sejahtera, dan hidup dalam kasih menjadi milik penuh orang Kristen ketika anugerah Roh Kudus itu Tuhan berikan.Di balik pengharapan itu pun ada suatu kebahagiaan tertinggi yang Tuhan janjikan (Roma 15:13; 5:5). Kebersamaan dengan Tuhan adalah hadiah dari kehidupan erat bersama Roh Kudus. Tuhan dalam pribadi Roh Kudus selalu berjalan beriring bersama orang percaya. Persekutuan bersama Roh Kudus di dunia ini adalah bermakna sama dengan persekutuan bersama Dia di surga nanti (Yohanes 14:20).

Roh Kudus wujud janji Tuhan Yesus untuk memberikan penyertaan selamanya kepada umatNya. Dia hanya akan diberikan bagi orang yang mengasihiNya, hal ini memberi ketegasan bahwa Roh Kudus akan berperan aktif dalam hidup seseorang dengan ikatan syarat kasih kepada Tuhan dan menggenapi segala kehendak-Nya. Ada hal terkemudian yang sama pentingnya Tuhan ingatkan yaitu dunia tidak mengenal keberadaan Roh Kudus, melihatpun tidak. Hikmat dari bumi tidak akan dapat menggapai pengenalan Allah. Hanya seseorang yang ada dalam kasih Tuhan akan mampu melihat dan merasa bahwa Dia ada. Kebersamaan dengan Roh Kudus akan mendatangkan hadiah Ilahi yang sama sekali berbeda dengan upah dunia (Yohanes 14:15-31).

\section{Roh Kudus dalam Hidup Orang Percaya}

Unsur terpenting dalam rencana keselamatan Allah Bapa adalah relasi. Sejak awal masa penciptaan, Allah menghendaki manusia memiliki relasi yang berkualitas tinggi denganNya yakni hubungan intim dan personal. Inkarnasi Tuhan untuk memulihkan relasi dengan Bapa. Melalui hubungan berkualitas, manusia akan memiliki cinta mendalam tertuju kepada penciptaNya. Ketika rasa cinta itu kuat maka secara otomatis akan terjalin interaksi antara manusia dan Allah yang semakin berkualitas yaitu dalam satu pikiran dan satu perasaan. Keadaan ini akan mendorong manusia bertindak terfokus hanya kepada Allah.

Inkarnasi Tuhan Yesus membuka relasi yang baru dengan Allah Bapa dan setelah kenaikanNya ke surga relasi itu diestafetkan kepada Roh Kudus. Tugas Roh Kudus dalam kehidupan orang Kristen sebagai penolong, penghibur, penuntun dan teman setia telah terbukti sejak masa jemaat mula-mula. Para rasul dan jemaat kala itu sangat bergantung hidup pada Roh Kudus. Ini disebabkan Roh Kuduslah yang membuka rahasia-rahasia Ilahi untuk disampaikan kepada jemaat mula-mula. Dan atas kehidupan yang demikian, Tuhan menganugerahkan kebahagiaan Ilahi bersama mereka. Inti dari berjalan bersama Roh Kudus adalah hidup yang dilandasi kekudusan, sehingga layak menjadi representasi atau saksi Ilahi. Seperti yang Tuhan ingatkan bahwa peran saksi berarti membawa kepada penyangkalan 
diri, pikul salib karena saksi berada dalam ikatan perjanjian dan kuasa Tuhan melalui RohNya.

Pengakuan iman dalam Kristus membawa kepada keyakinan keberadaan Roh Kudus sebagai bagian dari lembaga Ilahi trinitas, sekaligus sebagai janji Tuhan Yesus kepada muridNya. Namun fenomena dunia saat ini berlaku norma yang berbeda. Jemaat Tuhan tengah hidup di dunia yang bernorma dan cara berpikir yang tidak sama lagi dengan pengajaran Kekristenan. Semakin hari, norma dunia terlalu kuat mengikat hidup orang-orang Kristen. Kesadaran akan keberadaan dan kuasa Roh Kudus tidak diikuti dengan keterlibatanNya secara riil dalam kehidupan. Hal ini disebabkan dunia virtual dirasa lebih hidup dan nyata daripada keberadaan dan penyertaan Roh Kudus yang transenden. Ini dapat dipahami mengingat bahwa hanya sedikit orang Kristen yang sungguh-sungguh hidup bersama Roh Kudus dalam kesehariannya. Kehadiran Roh Kudus tidak akan bisa dirasakan oleh orang yang tidak bergaul erat dekat denganNya.

Ketidakmampuan merasakan kehadiran Roh Kudus adalah karena jiwa dan roh manusia telah penuh atau terselubung dengan hal-hal dunia. Sesuai dengan perkataan Tuhan dalam Yohanes 14:16-17 Roh Kudus sejatinya selalu ada dekat, bahkan diam di dalam roh orang percaya. Namun ada penghalang eksistensinya dalam diri orang percaya yaitu keduniawian, seperti yang Tuhan Yesus katakan bahwa dunia tidak menerima Dia lantaran keberadaanNya tidak dikenal. Padahal Roh Kudus memiliki kesejajaran dengan Tuhan Yesus dalam hal bimbingan dan pengajaran, sesuai dengan pernyataan Tuhan bahwa Roh Kudus sebagai penolong yang lain selain diriNya. Yohanes 14:15-31 menyatakan bahwa kehidupan bersama dengan Roh Kudus tidaklah serta merta, namun ada andil yang harus dilakukan oleh orang percaya. Kasih kepada Tuhan lah andil yang harus dipersembahkan. Bukanlah sebuah kasih yang murni jika tanpa melakukan kehendak Dia yang dikasihi. Ini berarti Roh Kudus ada tinggal bersama dengan orang percaya hanya ketika di dalamnya ada bersemayam kasih dan tindakan ketaatan sepenuhnya kepada Allah.

\section{Kajian Teologis Potret Kehidupan Dunia Virtual}

Dunia virtual pada masa ini adalah rumah besar tempat bertumbuhnya eksistensi diri manusia. Kebutuhan akan eksistensi diri saling bertemu dalam satu ruang dan terjalin menjadi satu kesatuan hasrat, gaya dan rupa. Dunia virtual seolah menyatukan masyarakat dunia menjadi satu warna yang sama dalam kehidupan. Karakter pada generasi teknologi berbeda dengan generasi lainnya, salah satunya berupa tingginya eksistensi diri atau keinginan atas pengakuan dari lingkungan. Eksistensi diri yang dibangun dalam dunia 
virtual menjadi semakin kokoh tatkala nilai-nilai yang dianut dan dikembangkan sama, yaitu nilai-nilai dunia. Dunia virtual merupakan potret kehidupan manusia akhir zaman seperti yang rasul Paulus tuliskan kepada Timotius: pada hari akhir manusia akan cinta diri dan mengagungkan uang (2 Timotius 3:1-5).

Hal ini telah terbukti di masa-masa kini, dunia virtual memuat tendensi perilaku narsistik dan telah bergeser menjadi wahana untuk memburu uang. Pada dasarnya narsistik adalah berfokus pada diri dan dapat berkembang menjadi hasrat keagungan diri. Hasil penelitian Dalimunthe menyebutkan bahwa narsistik dipengaruhi tingkat penerimaan diri. Semakin tinggi diri diterima oleh lingkungannya maka narsistik akan menurun demikian sebaliknya. Selain itu dunia virtual juga menyediakan ruang bagi orang-orang untuk mencari popularitas dan uang. Oleh karenanya hasrat ini menjadi semakin subur dan berkembang menjadi perilaku dan gaya yang bersifat general. Dunia virtual di era ini telah mendorong kebutuhan penghargaan dan aktualisasi diri menjadi kebutuhan primer manusia.

Dalam ranah keberagamaan, dunia virtual penuh hiruk pikuk penyajian pelbagai ajaran Kekristenan, namun hal tersebut banyak yang berujung pada saling silang opini dan kecaman. Muara dari hal ini adalah tetap kepada rasa diri paling benar dan memandang rendah orang lain. Para rohaniawan tidak mampu menampilkan pribadi Kristus dalam transparansinya ruang virtual. Gaya hidup dalam kemewahan justru ditampilkan tanpa ada rasa bersalah di mata jemaat. Penelitian Haryono dan Panuntun menyatakan bahwa hidup para pengkotbah masih dikuasai oleh dunia. Gaya hidup yang diterapkan adalah fokus penampilan dan menggunakan ukuran sukses versi dunia, sehingga seringkali pengkotbah berpakaian mahal dengan merk tertentu, menggunakan mobil dan rumah mewah dan gaya hidup hedon lainnya. Jawaban dari pertanyaan wawancara yang diajukan dalam riset tersebut menyatakan hal itu terjadi karena para pengkotbah belum selesai dalam proses penyangkalan diri atas kedagingan. Ini berarti firman Tuhan belum menjadi hidupnya.

Gambaran lain yang terjadi di dunia virtual adalah berkuasanya suara warganet. Suara-suara itu apapun bentuknya baik berupa komentar, nasihat, respon, ungkapan pikiran perasaan, dukungan bahkan berita bohong kesemuanya dapat berpengaruh dalam hidup seseorang. Oleh sebab itu di masa ini suara warganet dijadikan patokan dalam berperilaku dan pengambilan keputusan. Suara warganet telah dianggap sebuah kebenaran, sehingga muncul istilah warganet maha benar dengan pelbagai komennya. Sejatinya ruang virtual telah menciptakan dikotomis kebenaran.

Menganalisa fenomena-fenomena di atas, dapatlah dinyatakan bahwa kehidupan dalam dunia virtual tidak mencerminkan kehidupan bersama dengan Roh Kudus. Orang 
percaya mengabaikan kehadiranNya yang setia dalam kehidupan. Hal ini jelas dapat dikatakan demikian karena Roh Kudus yang mendiami orang percaya akan menggerakkan hidup dalam seluruh aspeknya. Hal ini berdampak pada perilaku dan fungsi keberadaan orang percaya yang hanya untuk kemuliaan Tuhan. Berkenaan dengan hal tersebut, umat percaya diharapkan dapat tergugah untuk memeriksa diri dan berani melakukan transformasi gaya hidup saat ini. Keberanian memutuskan, melawan arus kultur baru dan menampilkan gaya kehidupan yang selaras dengan kebenaran firman Tuhan menjadi tuntutan dan keniscayaan. Umat percaya disyaratkan untuk hanya memikirkan persoalan atau perkara surgawi, bukan duniawi (Kolose 3:2). Hal ini berarti menjalani kehidupan yang berbeda dengan format hidup dunia saat ini dengan menempatkan keteladanan hidup Tuhan Yesus sebagai padanan (1 Yohanes 2:6). Sehingga pada akhirnya umat percaya mampu menjadi saksi Tuhan, dan mewarnai kehidupan dunia virtual sebagai warna kemuliaan Tuhan melalui keteladanan dalam seluruh tatacara hidup (Kisah 1:4-11).

\section{KESIMPULAN}

Kehidupan dalam era virtual yang tidak melibatkan Roh Kudus di dalamnya akan terbentuk menjadi cerminan dunia semata. Sesuai dengan fungsinya Roh Kudus akan menuntun segala perkara hanya kepada kebenaran dan kemuliaan Tuhan. Faktanya, dunia virtual menggambarkan secara mayor warna keduniawian di dalamnya. Hal ini bukan berarti Roh Kudus tidak mampu mengintervensi keadaan, namun ini bertalian dengan kehendak bebas yang Tuhan berikan kepada orang percaya. Dunia virtual telah membelenggu manusia termasuk orang percaya dengan tipu muslihatnya agar hidup berpadanan dengannya dan mengambil sistem hidup yang diikatkan padanya. Genaplah apa yang Tuhan telah sampaikan bahwa dunia ini menuju kepada kebinasannya karena telah berada dalam kuasa musuhNya.

Namun sebagaimana yang Tuhan inginkan bagi umatNya untuk dapat menerangi dan menggarami dunia ini, maka umat percaya dapat berkontribusi nyata sebagai pemberi warna agar dunia virtual memancarkan kemuliaan Tuhan melalui beberapa langkah konkrit. Upaya tersebut antara lain: pertama, memutuskan untuk hidup fokus pada kekekalan, bukan pada masalah duniawi. Kedua, menjaga konsistensi hidup selalu dalam tuntunan Roh Kudus melalui kehidupan doa dan pembelajaran Alkitab secara benar sehingga dapat memberikan impartasi kebenaran Tuhan. Ketiga, berani mengekspresikan gaya hidup berbeda dalam dunia virtual dan dunia nyata, seperti misalnya hidup kesederhanaan, kelemahlembutan dan 
penguasaan diri pada segala hal. Keempat, secara aktif berupaya menjadi teladan dan saksi iman Kristen dalam setiap gerak interaksi dan komunikasi di dunia virtual

\section{REFERENSI}

Aderias Mesak Morib. "Pentingnya Pelayanan Konseling Pranikah.” Jurnal Teologi: Logon 3, no. 1 (August 9, 2020): 63-84. https://stteriksontritt.ac.id/ejournal/index.php/logon/article/view/19.

Anjaya, Carolina Etnasari, Yonatan Alex Arifianto, and Andreas Fernando. "Kecerdasan Spiritual Sebagai Dasar Terbentuknya Profesionalitas Guru Pendidikan Agama Kristen.” REDOMINATE: Jurnal Teologi Dan Pendidikan Kristiani 3, no. 1 (2021): 59-70.

Aprilia, Rizki, Aat Sriati, and Sri Hendrawati. "Tingkat Kecanduan Media Sosial Pada Remaja." Journal of Nursing Care 3, no. 1 (2020): 41-53. https://jurnal.unpad.ac.id/jnc/article/view/26928.

Arifianto, Yonatan Alex, and Asih sumiwi Rachmani. "Peran Roh Kudus Dalam Menuntun Orang Percaya Kepada Seluruh Kebenaran Berdasarkan Yohanes 16: 13." Jurnal Diegesis 3, no. 1 (2020): 1-12.

Budiyana, Hardi. "Roh Kudus Dalam Proses Pembelajaran Pendidikan Kristen Mewujudkan Pengajaran Kristen Yang Mengandung Nilai Kekal." Jurnal Teologi Berita Hidup 1, no. 1 (October 2018): 57-77. https://doi.org/10.38189/JTBH.V1I1.5.

Cantelon, Willard. Baptisan Roh Kudus. Kristen Indonesia. Malang: Yayasan Penerbit Gandum Mas, 2017. https://artikel.sabda.org/baptisan_roh_kudus.

Dalimunthe, Hairul Anwar, and Dinda Marito Br Sihombing. "Hubungan Penerimaan Diri Dengan Kecenderungan Narsistik Pada Mahasiswa Pengguna Instagram Di Universitas Medan Area." Journal of Education, Humaniora and Social Sciences (JEHSS) 2, no. 3 (April 2, 2020): 697-703. https://doi.org/10.34007/JEHSS.V2I3.144.

Gidion, Gidion. "Memahami Pekerjaan Roh Kudus Dalam Pelayanan Gereja Berdasarkan 1 Dan 2 Timotius." HARVESTER: Jurnal Teologi Dan Kepemimpinan Kristen 4, no. 2 (2020): 108-21. https://doi.org/10.52104/harvester.v4i2.14.

Goni, Moody. "Pengaruh Pemahaman Tentang Roh Kudus Terhadap Disiplin Rohani Mahasiswa." RHEMA: Jurnal Teologi Biblika Dan Praktika 5, no. 2 (2019): 8-23.

Haryono, Timotius, and Daniel Fajar Panuntun. "Model Gaya Hidup Nazir Sebagai Refleksi Gaya Hidup Hedon Pengkotbah Pada Zaman Milenial." Evangelikal: Jurnal Teologi Injili Dan Pembinaan Warga Jemaat 3, no. 2 (2019): 175. https://doi.org/10.46445/ejti.v3i2.146.

Hay, Ang Wie. "Gaya Hidup Digital Kristiani Era Globalisasi." Jurnal Youth Ministry 3, no. 1 (2015): 51-59. https://doi.org/10.47901/jym.v3i1.429.

Juditha, Christiany, Kheyene Molekandella Boer, Lidwina Mutia Sadasri, Rosalia Prismarini Nurdiarti, Arif Kusumawardhani, Rani Dwi Lestari, Astri Wulandari, et al. New Media \& Komunikasi Politik (Telaah Kontestasi Politik Dalam Ruang New Media). Edited by Mbridge Press. New Media $\backslash \&$ Komunikasi Politik. Yogyakarta, 2018.

Marpaung, Junierissa. "Pengaruh Penggunaan Gadget Dalam Kehidupan." KOPASTA: Jurnal Program Studi Bimbingan Konseling 5, no. 2 (2018). https://doi.org/10.33373/kop.v5i2.1521.

Nuraini, and Nelly Marhayati. "Analisis : Jurnal Studi Keislaman Peran Tasawuf Terhadap Masyarakat Modern.” Studi Keislaman 19, no. 2 (2019): 297-320.

Rakhman, Rizki Taufik. "Kategorisasi Imaji Visual Dalam Eksistensi Diri Generasi Digital Native." SENADA (Seminar Nasional Desain Dan Arsitektur) 3 (March 5, 2020): 176-

Copyright@2021; Ritornera - Jurnal Teologi Pentakosta Indonesia, ISSN 2797-7676 (online), 2797$717 \mathrm{x}$ (print) $\mid 10$ 
81. https://eprosiding.idbbali.ac.id/index.php/senada/article/view/292.

Riset. "Catatan Riset Remaja Pengguna Medsos.” Jakarta, 2021.

Sagala, Lenda Dabora. "Peran Pendidikan Agama Kristen Dalam Menghadapi Perubahan Sosial." Jurnal Simpson: Jurnal Teologi Dan Pendidikan Agama Kristen 1, no. 1 (2017): 48.

Setiawan, David Eko. "Kelahiran Baru Di Dalam Kristus Sebagai Titik Awal Pendidikan Karakter Unggul." Evangelikal: Jurnal Teologi Injili Dan Pembinaan Warga Jemaat 3, no. 2 (2019): 154. https://doi.org/10.46445/ejti.v3i2.135.

Setiawan, Hendro. Awam Mau Ke Mana. Yogyakarta: PT. Kanisius, 2016.

Simon. "Peran Roh Kudus Bagi Hamba Tuhan Dalam Merintis Gereja." LOGIA: Jurnal Teologi Pentakosta 1, no. 2 (2020): 41-64. http://sttberea.ac.id/ejournal/index.php/logia/article/view/33.

Stephanie, Conney. "Riset Ungkap Lebih Dari Separuh Penduduk Indonesia.” Kompas.com, 2021. https://tekno.kompas.com/read/2021/02/24/08050027/riset-ungkap-lebih-dariseparuh-penduduk-indonesia-melek-media-sosial.

Sumiwi, Asih Rachmani Endang. "Peran Roh Kudus Dalam Kehidupan Orang Percaya Masa Kini.” JURNAL TEOLOGI GRACIA DEO 1, no. 1 (December 14, 2018): 23-31. https://doi.org/10.46929/GRACIADEO.V1I1.19.

Tim. "Medsos Sebabkan Gangguan Mental Pada Orang Indonesia." CNN Indonesia, June 26, 2019. https://www.cnnindonesia.com/gaya-hidup/20190626100119-255406497/medsos-sebabkan-gangguan-mental-pada-orang-indonesia.

Tubagus, Steven, and Timotius Bakti Sarono. "Roh Kudus Dalam Trinitas Dan Komunitas Umat Tuhan (Holy Spirit in the Trinity and Community of God'S People)." QUAERENS: Journal of Theology and Christianity Studies 3, no. 1 (2021): 85-95. https://doi.org/10.46362/quaerens.v3i1.30.

Waani, Marciano Antaricksawan, and Ester Riyanti Supriadi. "Konfirmasi Teologis Peran Roh Kudus Dalam Pelayanan Gerejawi." Jurnal Teologi Dan Pendidikan Agama Kristen Sekolah Tinggi Teologi Anugrah Indonesia 1, no. 1 (2021): 37-53.

Yosa Putra, Daruliansyah. "Pengembangan Hubungan Interpersonal Remaja Di Sidoarjo Melalui Media Sosial.” Ilmu Komunikasi B1 (3), 2018, 1-2.

Zaluchu, Sonny Eli. "Metode Penelitian Di Dalam Manuskrip Jurnal Ilmiah Keagamaan." Jurnal Teologi Berita Hidup 3, no. 2 (2021): 249-66. https://doi.org/10.38189/jtbh.v3i2.93.

-. "Strategi Penelitian Kualitatif Dan Kuantitatif Di Dalam Penelitian Agama." Evangelikal: Jurnal Teologi Injili Dan Pembinaan Warga Jemaat 4, no. 1 (2020): 28. https://doi.org/10.46445/ejti.v4i1.167. 